\title{
Role of Tracheostomy in Respiratory Distress: A Study of 50 Cases
}

\section{Dimple Sahni}

\begin{abstract}
Tracheostomy plays a vital role in respiratory distress caused by different conditions, like respiratory passage of obstruction, head and neck tumor, surgeries, trauma patients and inflammatory conditions. Timing of the operation and postoperative care deserves more emphasis. Delay in the performance of this operation defeats the purpose of tracheostomy and if managed properly, it is a life saving procedure. The aim of the study was not only to give immediate relief to the patients of respiratory distress. But also to study age and sex distribution indication and evaluate factors associated with morbidity and mortality, intraoperative and postoperative complications associated with this procedure. This study was done on 50 cases of respiratory distress admitted in different department of Rajindra Hospital, Patiala, who underwent tracheostomy as an emergency or elective procedure. Most of the patients (24\%) were of 50 to 60 years of age of which $60 \%$ were males. Emergency tracheostomy was done in most of the cases (64\%). Most common complication was wound infection and granuloma formation (16\%). Mortality due to primary disease (tumors of head and neck) was $34 \%$. Followed by head injury (29\%). Only one patient died of tracheostomy due to excessive bleeding.
\end{abstract}

Keywords: Percutaneous dilation tracheostomy, Respiratory distress, Tracheostomy.

How to cite this article: Sahni D. Role of Tracheostomy in Respiratory Distress: A Study of 50 Cases. Clin Rhinol An Int J 2015;8(1):20-23.

\section{Source of support: Nil}

Conflict of interest: None

\section{INTRODUCTION}

Attempts to save man's life from suffocation has been made from ancient times. Homer ${ }^{1}$ around $1000 \mathrm{BC}$ reported that Alexander the great saved life of one of his soldiers from suffocation by making an opening in trachea with the tip of his sword. Tracheostomy means creating a window in the anterior wall of trachea. Heister ${ }^{2}$ was the first to use the word tracheostomy in 1739. Surgical tracheostomy was standardized by Jackson in $1902 .^{3}$

\footnotetext{
Assistant Professor

Department of ENT, Government Medical College, Patiala Punjab, India

Corresponding Author: Dimple Sahni, Assistant Professor Department of ENT, Government Medical College, Patiala Punjab, India, Phone: 09417222119, e-mail: sawhneygirish@ gmail.com
}

Tracheostomy serves as a bypass for mechanical obstruction of the upper respiratory passages. It also facilitates intermittent positive pressure respiration when artificial ventilation is needed. It bypasses the pool of saliva in the pharynx and when laryngeal reflexes are ineffective, and hence protects the air passages against aspiration. It removes the accumulated secretions in the lower air passages. It reduces the anatomical dead space to nearly $50 \%$ of normal.

Tracheostomy gives access to tracheobronchial tree for the aspiration of obstructing secretions, administration of drugs and the encouragement of maximum respiratory efficiency in a handicapped pulmonary system.

Since tracheostomy is an operation that 'opens the doors of breadth', it is not surprising that along with its widening use and the technical improvements, it is not without potential life threatening complications, if not managed properly. Probably no other surgical procedure produces such a dramatic improvement as tracheostomy does, whenever indicated.

However, if performed properly, selecting cases judiciously, providing an efficient postoperative care to such a patient, tracheostomy can be a life saving procdure. These days percutanous dilatation tracheostomy is increasingly accepted procedure for bed side tracheostomy but University of California found that bed side percutaneous dilatation tracheostomy is not far better than bed side open tracheostomy if long term results are observed Porter and Ivatury. ${ }^{4}$ Mayer et $\mathrm{al}^{5}$ concluded that trained physicians can safely perform bed side percutaneous dilatation tracheostony after previous tracheostomy.

\section{MATERIALS AND METHODS}

The present study was undertaken on 50 patients of respiratory distress who were treated with tracheostomy the study was done in ENT department, Rajindra Hospital, Patiala. Diagnosis, indication and complications of tracheostomy were recorded. Tracheostomy was done without any prior organization and preparation was labeled as emergency tracheostomy and those done with some preparation and organization was labeled as elective tracheostomy. The improvement was noted the complications were also recorded. All patients were followed up 
from few days to few months and after decannulation depending upon the case. X-rays and tracheal swabs were taken wherever require.

It was done under local or general anesthesia as needed. Premedication was given patient was made to lie supine with pillow under shoulder so that neck was extended. Two persons xylocaine with adrenalin was infiltrated in line of incision a vertical incision was made in the midline of the neck from cricoids cartilage two finger sternal notch. This incision gave rapid access with minimum bleeding in case of emergency surgery. Transfer incision was given in case of elective procedure as it had advantage of cosmetically better scar. Blunt dissection was done. Skin subcutaneous tissue, strap muscles were retracted. Pretracheal fascia was incised. An oval window was created in anterior wall of trachea at the level of second-fourth tracheal ring. Portex tracheostomy tube of appropriate size was inserted and secured by tapes. Tube was changed after 72 hours. Any secretion or blood coming out of tube was removed by suction operators. Decannulation was done with decreasing size of tube in patient with temporary tracheostomy.

\section{OBSERVATIONS}

Fifty patients having respiratory distress in whom tracheostomy was done were selected for the study.

Age: Most of the patients belonged to 50 to 60 years (Table 1).

Sex distribution: Sixty percent of the total cases were males and $40 \%$ were females (Table 2 ).

Disease pattern: The maximum number of patients needed tracheostomy for head and neck tumors (50\%) followed by head injury (12\%) (Table 3 ).

Type of tracheostomy: Sixty-four percent of cases had temporary tracheostomy while $36 \%$ had permanent tracheostomy (Table 4).

Kind of tracheostomy: Sixty-four percent of cases underwent emergency tracheostomy while 36\% underwent elective tracheostomy (Table 5).

Morbidity: There were 25 complications occurring in 50 patients which were related to tracheostomy. Thus, morbidity due to tracheostomy was 50\% (Table 6).

Mortality: There were 17 deaths due to primary disease and one death due to tracheostomy.

\section{Decannulation}

Decannulation was done in 16 cases who survived after temporary tracheostomy. There were five cases (31\%) in which decannulation was done within 6 days, seven cases
Table 1: Age distribution

\begin{tabular}{lll}
\hline Age groups (in years) & No. of cases & Percentage age \\
\hline $0-5$ & 5 & 10 \\
$6-10$ & 6 & 12 \\
$11-20$ & 2 & 4 \\
$21-30$ & 5 & 10 \\
$31-40$ & 9 & 18 \\
$41-50$ & 9 & 18 \\
$51-60$ & 12 & 24 \\
60 onwards & 2 & 4 \\
\hline Total & 50 & 100 \\
\hline
\end{tabular}

Table 2: Sex distribution

\begin{tabular}{lll}
\hline Sex & No. of cases & Percentage age \\
\hline Male & 30 & 60 \\
Female & 20 & 40 \\
\hline
\end{tabular}

Table 3: Disease pattern

\begin{tabular}{lll}
\hline Disease & Total cases & Percentage \\
\hline Head and neck tumors & & \\
$\begin{array}{l}\text { a. Carcinoma larynx } \\
\text { b. Carcinoma tonsil, tongue, }\end{array}$ & 15 & 30 \\
$\quad$ epiglottis and floor of mouth & & 16 \\
c. Vocal polyposis & 2 & 4 \\
Head injury & 6 & 12 \\
Acute tracheobronchitis & 5 & 10 \\
Burns & 4 & 8 \\
Foreign body larynx & 3 & 6 \\
Cardiorespiratory arrest & 2 & 4 \\
Tetanus & 2 & 4 \\
Acute transverse myelitis & 1 & 2 \\
Neck trauma & 1 & 2 \\
Laryngeal stenosis & 1 & 2 \\
\hline Total & 50 & 100 \\
\hline
\end{tabular}

Table 4: Type of tracheostomy

\begin{tabular}{lll}
\hline Type of tracheostomy & No. of patients & Percentage \\
\hline Temporary & 32 & 64 \\
Permanent & 18 & 36 \\
\hline Total & 50 & 100 \\
\hline
\end{tabular}

Table 5: Kind of tracheostomy

\begin{tabular}{lll}
\hline Type of tracheostomy & No. of patients & Percentage \\
\hline Emergency & 32 & 64 \\
Elective & 18 & 36 \\
\hline Total & 50 & 100 \\
\hline
\end{tabular}

Table 6: Postoperative complications

\begin{tabular}{lll}
\hline Name of complications & No. of cases & Percentage \\
\hline Wound infection and granuloma & 8 & 16 \\
Subcutaneous emphysema & 5 & 10 \\
Tracheobronchitis & 4 & 8 \\
Delayed closure of wound & 2 & 4 \\
Hemorrhage & 1 & 2 \\
Apnea cardiorespiratory arrest & 1 & 2 \\
Tracheoesophageal fistula & 1 & 2 \\
Laryngeal stenosis & 1 & 2 \\
Difficult decannulation & 1 & 2 \\
\hline
\end{tabular}




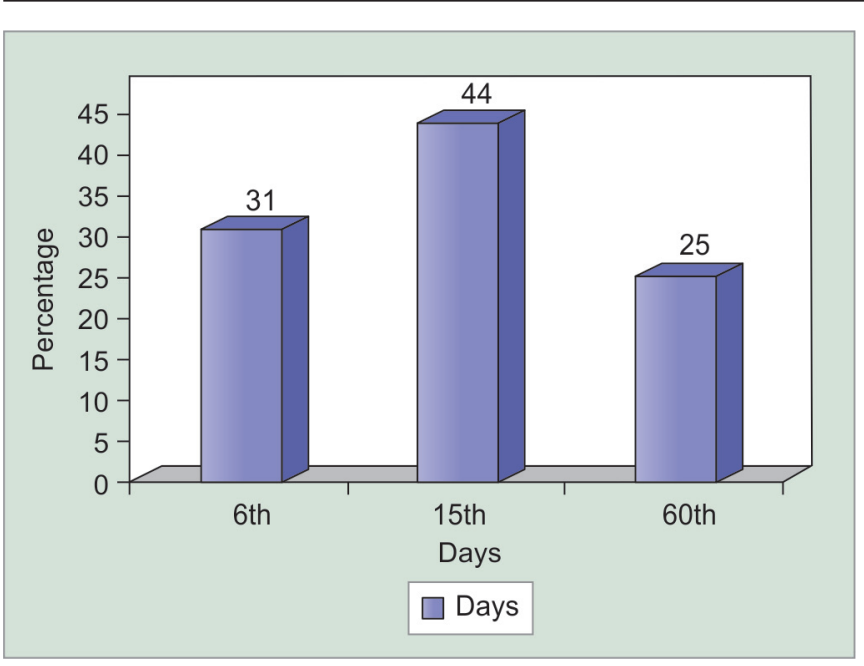

Graph 1: Decannulation

$(44 \%)$ within 15 days and only four cases (25\%) in which the decannulation was done within 60 days as shown in the Graph 1.

\section{DISCUSSION}

The age of the patients varied from 1 year to 65 years. Eighteen percent of the cases were under the age of 10 years. Sixty percent of patients were in the age group of 31 to 60 years, and only $4 \%$ were above the age of 60 years. There are limited indications for tracheostomy in pediatric patients because they can be kept intubated for a longer duration as compared to adults.

Chakroborty and Bhattachary ${ }^{6}$ concluded that out of 170 cases in whom tracheostomy was performed 722 patients were under age of 10 years $(42.4 \%)$, 39 patients were between 11 and $40(22.9 \%)$ and 59 patients were above the age of 40 years $(33.7 \%)$.

There were $30(60 \%)$ males and $20(40 \%)$ females in our study with ratio of 3:2. This can be explained on the basis that head and neck tumors and head injury are more common in males-possibly because males are more exposed to physical and psychological trauma.

In our study, $50 \%$ patients needed tracheostomy for head and neck tumors. Chakroborty and Bhattachary ${ }^{6}$ reported that malignant tumors of larynx and laryngopharynx requiring tracheostomy constituted $35 \%$. We had higher incidence of tracheostomy in head and neck tumor because of low socioeconomic status of patients suffering from cancer. They attended the hospitals in advanced stage with respiratory distress when the doctors had no alternative but to do tracheostomy to save patient's life.

In our study, $12 \%$ of patients with head injury required tracheostomy for establishment. In our series of 50 cases, 32 cases $(64 \%)$ required temporary tracheobronchitis, burns, head injury and foreign body larynx. Permanent tracheostomy was done in 18 cases (36\%) needed in carcinoma head and neck. Emergency tracheostmoy was needed in most cases of functional ventilatory obstruction and secretional obstruction. Elective tracheostomy was needed in carcinoma head and neck. In study of Choudhary and Sultan $\mathrm{T}^{7}$ the common indication of elective tracheostomy was intracranial space occupying lesion $(26.6 \%)$ and head injury $26.67 \%$ whereas commonest indication of emergency tracheostomy was laryngeal carcinoma (53.33\%).

The complication rate in our series was $50 \%$. While in Dugan and Samson Series, ${ }^{8}$ it was $36.3 \%$, whereas Ilce ${ }^{9}$ reported $29 \%$ complication rate in his series.

The higher complication rate in our study was because we had much more decompensated patients or the patients were brought in the late stages of disease. In our study, there were 12 cases of infection out of which eight cases $(16 \%)$ were of wound infection and granuloma formation. This being the commonest complication in our series. Four cases were of tracheobronchitis, whereas in Chakroborty and Bhattachary series, only $7 \%$ cases of wound infection were there.

In our series, as many as five cases $(10 \%)$ developed subcutaneous emphysema, whereas the incidence of pneumothorax, pneumomediastinum and subcutaneous emphysema was $13 \%$ in Oliver and Rankak study ${ }^{10}$ in children. While Mulder ${ }^{11}$ reported the incidence of intrathoracic complications (subcutaneous emphysema, pnemothorax and pneumomediastinum) of $10 \%$.

In our study, one patient $(2 \%)$ had severe hemorrhage during the procedure and it was fatal. The probable cause of intraoperative bleeding was inadequate hemostasis.

Chakroborty and Bhattachary reported incidence of hemorrhage in $19.4 \%$ cases but bleeding was minimal and did not prove lethal.

In two of our cases (4\%), there was delayed closure of the tracheostomy wound. The wound did not heal within a week after decannulation. Chakroborty and Bhattachary ${ }^{6}$ reported difficult decannulation and delayed closure of wound in $6.5 \%$ cases.

There was one case of laryngeal stenosis in our series. In this case, patient had neck injury as a cause of respiratory distress. In which emergency tracheostomy was done. Majority of the cases, i.e. $28 \%(56 \%)$ in our series, tracheostomy for upper airway obstruction. In $14 \%$ cases, it was done for functional ventilator obstruction. Decannulation was done in 16 cases who survive after temporary tracheostomy and most of these cases were of acute tracheobronchitis vocal polyposes and bones. Whereas in Prescott and Vanlierde ${ }^{12}$ reported that out of 162 cases decannulation was done in $58 \%$ cases within 4 weeks and $75 \%$ cases within 10 weeks.

In our series, there were total 18 deaths, out of which one was due to excessive hemorrhage during the procedure. Whereas in Dugan and Samson series mortality was 
$48 \%$ in 461 patients, mortality in Ilce et al series was 59\%. They reported one death due to tracheostomy procedure.

Gilbey $^{13}$ reported fatal complication of percutaneous dilatation tracheostomy due to vascular injury if there is pulsation over trachea due to aberrant vessels. Then conventional open tracheostomy.

Lee and $\mathrm{Lam}^{14}$ in a study observed that in a case of acute life threatening acute epiglottitis the immediate treatment is emergency tracheostomy with broad spectrum antibiotics.

\section{CONCLUSION}

Tracheostomy has a very useful role in respiratory distress in cases of head and neck malignancy, in planned surgery, and in various other diseases. Delay in performance of this operation defeats the purpose of tracheostomy and undoubtedly accounts for a large part of the high mortality. Tracheostomy is an operation attended with definite risks. There is morbidity and mortality related directly to this procedure. If managed properly it is life saving procedure and we should continue to explore its potentiality.

\section{REFERENCES}

1. Homer (931-1120). Quoted from story of tracheostomy. Brit J Child Dis 1934;31:253.
2. Heister M (1739). Quoted from story of tracheostomy. Brit J Child Dis 1934;31:260.

3. Jackson C. Tracheostomy and other errors, the chief causes of chronic laryngeal stenosis. Surg Gynec Obst 1921;32:392.

4. Porter JM, Ivatury RR. Preferred route of tracheostomy percutaneous versus open at bed side. Am Surg 1999;65(2): 142-146.

5. Meyer M, Critchlow J, Mansharamani N, et al. Repeat bedside percutaneous dilatational tracheostomy is a safe procedure. Crit Care Med 2002;30(5):986-988.

6. Chakroborty A, Bhattachary AK. Tracheostomy in management of respiratory distress-a 10 years review. Ind J Otorhinolaryngol 1995;47(3):30-32.

7. Choudhary AA, Sultan T. A comparative study of elective and emergency tracheostomy. Bangladesh J Otolaryngol 2008;14(2):57-62.

8. Dugan DJ, Samson PC. Tracheostomy: present day indications and techniques. Am Jr Surg 1963;106:290.

9. Ilce Z, Celayir S, Tekand G. Tracheostomy in childhood: 20 years experience from a pediatric surgery clinic. Pediatr Int 2002;44(3):306-309.

10. Oliver P, Rankak K. Tracheostomy in children. New Eng J Med 1962;261:631.

11. Mulder DS. Complications of tracheostomy: relationship to long-term ventilator assistance. Jr Trauma 1969;95:389.

12. Prescott CA, Vanlierde MJ. Trach in children. Int J Paediat Otolaryngol 1989;17:97-107.

13. Gilbey P. Fatal complications of percutaneous dilatation tracheostomy. Am J Otolaryngol 2012;33(6):770-773.

14. Lee AC, Lam SY. Life threatening acute epiglottitis in acute leukemia. Leuk Lymphoma 2002;43(3):665-657. 